\title{
The role of phosphate-containing medications and low dietary phosphorus- protein ratio in reducing intestinal phosphorus load in patients with chronic kidney disease
}

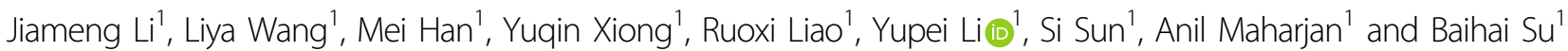

\begin{abstract}
Chronic kidney disease-mineral and bone disorder (CKD-MBD) is a common complication in patients experiencing end-stage renal disease (ESRD). It includes abnormalities in bone and mineral metabolism and vascular calcification. Hyperphosphatemia is a major risk factor leading to morbidity and mortality in patients with chronic kidney disease. Increased mortality has been observed in patients with ESRD, with serum phosphorus levels of $>5.5 \mathrm{mg} / \mathrm{dL}$. Therefore, control of hyperphosphatemia is a major therapeutic goal in the prevention and treatment of CKD-MBD. The treatment of hyperphosphatemia includes decreasing intestinal phosphorus load and increasing renal phosphorus removal. Decreasing the intestinal load of phosphorus plays a major role in the prevention and treatment of CKD-MBD. Among the dietary sources of phosphorus, some of the commonly prescribed medications have also been reported to contain phosphorus. However, drugs are often ignored even though they act as a potential source of phosphorus. Similarly, although proteins are the major source of dietary phosphorus, reducing protein intake can increase mortality in patients with CKD. Recently, the importance of phosphorus/protein ratio in food have been reported to be a sensitive marker for controlling dietary intake of phosphorus. This review summarizes the progress in the research on phosphate content in drugs as an excipient and the various aspects of dietary management of hyperphosphatemia in patients with CKD, with special emphasis on dietary restriction of phosphorus with low dietary phosphate/protein ratio.
\end{abstract}

\section{Introduction}

Chronic kidney disease-mineral and bone disorder (CKD-MBD) is a recently acknowledged metabolic abnormality, proposed in 2006 by the Kidney Disease: Improving Global Outcomes (KDIGO) working group. This distinct naming of varied clinical syndromes (CKD$\mathrm{MBD}$ ) that develop due to impaired mineral regulation in chronic kidney disease (CKD) was to differentiate it from

Correspondence: Baihai Su (imsbh@163.com)

'Department of Nephrology, West China Hospital, Sichuan University, 610041 Chengdu, China

These authors contributed equally: Jiameng Li, Liya Wang. the histologically well-defined renal osteodystrophy ${ }^{1}$. CKD-MBD is considered to be a progressive disorder, affecting the homeostasis among the renal, skeletal, and cardiovascular (CV) systems, thereby leading to a kidney-bone-vascular axis pathophysiological hypothesis $^{1,2}$. The classical clinical manifestations of CKD-MBD defined by the KDIGO clinical practice guidelines also reaffirms the kidney-bone-vascular axis hypothesis. The clinical features of CKD-MBD are primarily due to the compromised renal excretion of minerals, leading to abnormality in circulating calcium, phosphorous, parathyroid hormone $(\mathrm{PTH})$, and vitamin $\mathrm{D}$. The secondary

\section{(c) The Author(s) 2019}

(c) (i) Open Access This article is licensed under a Creative Commons Attribution 4.0 International License, which permits use, sharing, adaptation, distribution and reproduction c. in any medium or format, as long as you give appropriate credit to the original author(s) and the source, provide a link to the Creative Commons license, and indicate if changes were made. The images or other third party material in this article are included in the article's Creative Commons license, unless indicated otherwise in a credit line to the material. If material is not included in the article's Creative Commons license and your intended use is not permitted by statutory regulation or exceeds the permitted use, you will need to obtain permission directly from the copyright holder. To view a copy of this license, visit http://creativecommons.org/licenses/by/4.0/. 
effects of this renal insufficiency include abnormalities in bone turnover, mineralization, volume, linear growth, strength, and ectopic calcification (vascular and soft tissues) $^{3}$.

Among the different pathogenic factors, phosphate homeostasis is one of the initiating factors for the onset of CKD-MBD, which is initiated during early stages of CKD. This anomaly in phosphate homeostasis was evidently shown by elevated fibroblast growth factor 23 (FGF23) levels (hormone-regulating phosphate excretion) in early stages of $\mathrm{CKD}^{4}$. The two main homeostatic mechanisms that regulate circulating phosphates are intestinal absorption and renal excretion. While intestinal absorption depends on the dietary pattern, renal excretion promotes removal of excess phosphates even in case of phosphate-rich diet through regulation of FGF23 and $\mathrm{PTH}^{5,6}$. In individuals with normal renal function, this is facilitated by decreased reabsorption of phosphates, which is mediated by downregulation of sodium phosphate cotransporters in the proximal tubule of the nephrons ${ }^{7,8}$. However, in case of patients with CKD, the progressive reduction in glomerular filtration leads to further decrease in phosphate reabsorption, which compensates the renal insufficiency during the early stages of CKD. In CKD stages 3 to $5\left(\mathrm{eGFR}<60 \mathrm{~mL} / \mathrm{min} / 1.73 \mathrm{~m}^{2}\right)$, the phosphate homeostatic mechanism is totally lost leading to increase in circulating phosphates and inorganic phosphorous $(\mathrm{Pi})$, which is defined as hyperphosphatemia ${ }^{9,10}$.

Although the pathogenic basis of hyperphosphatemia in CKD is renal insufficiency, the clinical manifestations of CKD-MBD are mainly due to the adaptive response mediated by PTH and FGF23. Elevated PTH induces excess bone resorption of phosphates, which exceeds bone formation, leading to osteoporosis and other skeletal structure abnormalities. Furthermore, since skeletal structures could no longer act as phosphate reservoirs, soft tissues and vasculatures become secondary reservoirs, thereby leading to their calcification and increasing $\mathrm{CV}$ morbidity and mortality in patients with $\mathrm{CKD}^{11-14}$.

Hyperphosphatemia in patients with CKD, apart from inducing secondary hyperparathyroidism and renal osteodystrophy, CV calcification is also an important prognostic factor for morbidity and mortality in patients with end-stage renal disease (ESRD) undergoing dialysis $^{15-20}$. The prognostic role of serum phosphorous as a modifiable risk factor has also been reported in multiple observational studies, highlighting the potential effect of lowering blood phosphorous (Pi and phosphates) in CKD$\mathrm{MBD}^{17,21,22}$. This was also substantiated in a metaanalysis including a total of 4651 patients with nondialysis CKD, in whom a $35 \%$ increase in mortality was observed per mg increase in phosphate ${ }^{23}$.

The therapeutic management of hyperphosphatemia includes decreasing intestinal absorption of phosphorus and increasing its renal removal. The former includes dietary restriction to reduce phosphorus intake $\mathrm{e}^{24-27}$ and a phosphorus binder to reduce oral phosphorus absorption $^{15,16,28}$. The latter includes regular dialysis to remove blood phosphorus, which is considered to be of limited value in removal of phosphates, highlighting the importance of dietary restriction ${ }^{29,30}$. Owing to the fact that proteins are the main source of dietary phosphates, which is difficult to restrict, dietary control of phosphates has its own pitfalls. ${ }^{10}$ Furthermore, when it comes to patients with CKD, an often ignored source of dietary phosphate is the long-term multiple medications, some of which have been reported to contain phosphate ${ }^{31,32}$. This review provides an overview of the various aspects of dietary management of hyperphosphatemia in patients with CKD, with special emphasis on reducing intestinal phosphorus load in those patients by careful prescription of phosphate-containing medications and dietary restriction in terms of low dietary phosphate/protein ratio. To the best of our knowledge, this is the first review highlighting the phosphorus content in medications prescribed to patients with CKD.

\section{Phosphorus content in CKD medication}

Other than dairy or protein-based food products, which are rich in dietary phosphates, there is yet another source of dietary phosphorus that has remained unrecognized, i.e., the phosphorus content of medications prescribed for patients undergoing dialysis ${ }^{32,33}$. In pharmaceutical preparation, phosphates are used both as an active pharmaceutical ingredient (API; such as bisphosphonates) or as a drug counterion (e.g., betamethasone sodium phosphate), or most commonly as an excipient (e.g., anhydrous calcium hydrogen phosphate). This also includes some of the available drugs used for the treatment of CKD in which the most common role of phosphorus is as an excipient $^{34,35}$.

\section{Phosphorus as a pharmaceutical excipient}

The largely unrecognized role of phosphorus content in medication is mainly due to its role in pharmaceutical preparations. It is mostly used as a pharmaceutical excipient, which in most cases is reported on the packaging label without the precise concentration ${ }^{33}$. Phosphates as excipients are most commonly used as diluents, buffers to prevent $\mathrm{pH}$ fluctuations, and provide the required density for the preparation, thereby facilitating appropriate route of administration ${ }^{32,36}$. Although excipients are often considered as pharmacologically inert ingredients, they could also have iatrogenic effects as shown by diethylene glycol in sulfanilamide, which caused acute kidney injury, killing more than 100 people in the $\mathrm{US}^{37}$. The phosphorus-containing excipients in drugs are not inert as they increase the phosphorus intake and thereby 
increase the blood phosphorus levels that could have potential iatrogenic effects ${ }^{35}$. Although the phosphorus content in excipients usually contribute to only a small fraction of the recommended daily intake, it is still clinically significant in terms of treating patients with CKD because most of these patients will be on multiple medications $^{38}$. Polypharmacy is a major problem for patients with ESRD due to the burden of multiple comorbidities and dialysis-related complications caused by $i^{38,39}$. In a study of 233 patients undergoing chronic hemodialysis (HD), more than a quarter of the patients were prescribed $>25$ tablets per day with a median daily pill burden of 19 (refs. ${ }^{35,38}$ ). If most of the medications consumed by patients undergoing dialysis contain phosphate, then this will significantly contribute to daily phosphorus intake of these patients, which may contribute to the progression of CKD-MBD. Although the number of phosphate-binder pills taken by the patient is not accounted for in this study, the phosphate burden due to medication is significant $^{35}$.

\section{Phosphorus-containing drugs should not be overlooked}

Patients with CKD are usually prescribed a daily dose of multiple medications, and hence, drugs are an important source of phosphorus intake that cannot be ignored. Commonly used drugs for long-term oral administration in patients with CKD alleviate comorbidities related to $\mathrm{CV}$ system and central nervous system (CNS). The different medications include antihypertensives, anticoagulants, immunosuppressants, hypoglycemic agents, lipid-lowering drugs, analgesics, antihistamines, antidepressants, anti-gout drugs, and gastrointestinal drugs ${ }^{35,36}$. A potential confounder in estimating the medicinal phosphorus content is the wide variation observed with different formulations of the same drug from different manufactures, which has been highlighted in previous studies ${ }^{31,35}$. Although the label usually mentions that the drug contains phosphorus (usually shown in the excipient list), the label does not specify the exact quantity of phosphorous present ${ }^{31}$.

The extent of the problem was highlighted by a landmark study by Sherman et al., who reviewed the phosphorus content mentioned in the package inserts of hemodialytic medications and also confirmed the precise concentration of phosphorus by colorimetric methods. They analyzed different doses of both the branded and generic forms of multiple drugs and reported doseindependent variations in phosphorus content between branded and generic formulations. They identified 12 prescription drugs containing phosphorus, with 9 of them being prescribed for a daily dose of $>10 \mathrm{mg}$. Phosphorus was identified in both branded and generic forms of amlodipine, lisinopril, paroxetine, and bisoprolol. On the basis of their preliminary study, they also hypothesized that when the branded form of a drug is phosphorus-free, then the generic form may also be phosphorus-free. Although contrary to their hypothesis, they observed generic form of paroxetine to contain lower concentration of phosphorus than the branded version ${ }^{31}$. In a subsequent large-scale analysis by the same authors, 200 most commonly prescribed branded medications used in the dialysis centers of the US-based Dialysis Clinic, Inc. (Nashville, TN) were analyzed and reported 23 branded formulations (11.5\%) to contain phosphorus in their label. As they could not ascertain the phosphorus content from the drug manufacturers, they estimated the phosphorus content of multiple doses of branded and generic formulations by spectroscopy-based method. They reported the amount of phosphorus to vary from $1.4 \mathrm{mg} /$ tablet (clonidine: $0.2 \mathrm{mg}$; BluePoint Laboratories, Dublin, Ireland) to $111.5 \mathrm{mg}$ (paroxetine: $40 \mathrm{mg}$; GlaxoSmithKline, Philadelphia, PA). The branded versus generic comparison revealed results similar to their earlier study. Furthermore, in order to confirm their hypothesis with respect to the absence of phosphorus in generic form, provided the branded form is phosphorus-free, they analyzed 91 generic drugs and found phosphorus in only 1 generic drug (Pravachol, Eon) despite the absence of phosphorus in its branded form ${ }^{31,33}$. The phosphate content of the various commonly prescribed drugs is represented in Table 1.

The phosphorus content of branded versus generic formulation issue was also addressed by a similar study conducted by Shimoishi et al., with 22 widely prescribed medications for patients undergoing HD in Japan. They also reported branded formulations such as amlodipine and paroxetine to be rich in phosphorus content among the study drugs. In case of paroxetine, all the generic formulations contained lower levels of phosphorus compared with the branded formulations, which was in concurrence to the study by Sherman et al., whereas in case of amlodipine, the results were mixed with few generic formulations having higher levels of phosphorus compared with the branded formulations ${ }^{31,32}$. However, as the number of drugs examined by Shimoishi et al. was relatively low, the precise nature of branded and generic formulations may require further studies.

In a similar study, Nelson et al. calculated both the consumed and estimated medicinal phosphorus loads in 101 Canadian patients undergoing HD. They analyzed 1744 drug formulations of 124 different drugs prescribed to patients undergoing HD and found that a total of 185 (11\%) drug formulations contained phosphorus as per the drug monographs obtained from the Health Canada Drug Database. In order to find the precise amount of phosphorus, they contacted 26 drug manufacturers, out of which 18 manufacturers revealed the phosphorus content. Among the phosphorus-containing drugs, $65 \%$ of the drugs were prescribed for CNS-related comorbidities, 
Table 1 Phosphorus content in commonly prescribed medications to patients undergoing dialysis

\begin{tabular}{|c|c|c|}
\hline $\begin{array}{l}\text { Medication: } \\
\text { Dosage (mg) }\end{array}$ & $\begin{array}{l}\text { Content of Available } \\
\text { Phosphorus (mg) }\end{array}$ & Manufacturer \\
\hline \multicolumn{3}{|l|}{ Amlodipine } \\
\hline 5 & 13.4 & Pfizer Inc \\
\hline 5 & 3.8 & Camber Pharm \\
\hline 10 & 7.9 & Camber Pharm \\
\hline 10 & 40.1 & Qualitest \\
\hline 5 & 4.9 & Lupin \\
\hline 10 & 8.6 & Lupin \\
\hline 5 & 14.0 & Greenstone Brand \\
\hline 2.5 & 25.99 & $\begin{array}{l}\text { Actavis Speciality } \\
\text { Pharmaceuticals Co. }\end{array}$ \\
\hline 5 & 51.99 & $\begin{array}{l}\text { Actavis Speciality } \\
\text { Pharmaceuticals Co. }\end{array}$ \\
\hline 10 & 103.9 & $\begin{array}{l}\text { Actavis Speciality } \\
\text { Pharmaceuticals Co. }\end{array}$ \\
\hline 2.5 & NA & Auro Pharma Inc. \\
\hline 5 & 36 & Auro Pharma Inc. \\
\hline 10 & 72 & Auro Pharma Inc. \\
\hline 2.5 & 20.9 & $\begin{array}{l}\text { JAMP Pharma } \\
\text { Corporation }\end{array}$ \\
\hline 5 & 41.88 & $\begin{array}{l}\text { JAMP Pharma } \\
\text { Corporation }\end{array}$ \\
\hline 10 & 83.8 & $\begin{array}{l}\text { JAMP Pharma } \\
\text { Corporation }\end{array}$ \\
\hline 2.5 & 22.4 & Laboratoire Riva Inc. \\
\hline 5 & 44.8 & Laboratoire Riva Inc. \\
\hline 10 & 89.6 & Laboratoire Riva Inc. \\
\hline 2.5 & NA & Mint Pharmaceuticals Inc. \\
\hline 5 & 6.9 & Mint Pharmaceuticals Inc \\
\hline 10 & 13.8 & Mint Pharmaceuticals Inc \\
\hline 2.5 & 22.1 & Pharmascience Inc. \\
\hline 5 & 44.3 & Pharmascience Inc. \\
\hline 10 & 88.6 & Pharmascience Inc. \\
\hline 2.5 & NA & Pfizer Canada Inc. \\
\hline 5 & 44 & Pfizer Canada Inc. \\
\hline 10 & 88 & Pfizer Canada Inc. \\
\hline 2.5 & 29.1 & Sandoz Canada Inc. \\
\hline 5 & 58.3 & Sandoz Canada Inc. \\
\hline 10 & 116.6 & Sandoz Canada Inc. \\
\hline 2.5 & 22.7 & Sivem Pharmaceuticals \\
\hline 5 & 45.4 & Sivem Pharmaceuticals \\
\hline 10 & 90.8 & Sivem Pharmaceuticals \\
\hline 2.5 & NA & Teva Canada Ltd. \\
\hline 5 & 82.8 & Teva Canada Ltd. \\
\hline 10 & 165.6 & Teva Canada Ltd. \\
\hline \multicolumn{3}{|l|}{ Lisinopril } \\
\hline 5 & 3.6 & Lupin \\
\hline 20 & 7.4 & Lupin \\
\hline 5 & 18.4 & Blue Point Laboratories \\
\hline 10 & 32.6 & Blue Point Laboratories \\
\hline 20 & 20.8 & Blue Point Laboratories \\
\hline 30 & 27.4 & Blue Point Laboratories \\
\hline 40 & 30.8 & Blue Point Laboratories \\
\hline 10 & 21.4 & Merck \\
\hline
\end{tabular}

Table 1 continued

\begin{tabular}{|c|c|c|}
\hline $\begin{array}{l}\text { Medication: } \\
\text { Dosage (mg) }\end{array}$ & $\begin{array}{l}\text { Content of Available } \\
\text { Phosphorus (mg) }\end{array}$ & Manufacturer \\
\hline 20 & 22.0 & Merck \\
\hline 10 & 28.9 & Sandoz \\
\hline 20 & 30.7 & Sandoz \\
\hline 40 & 26.2 & Sandoz \\
\hline \multicolumn{3}{|l|}{ Rosuvastatin } \\
\hline 5 & 1.9 & AstraZeneca \\
\hline 10 & 1.8 & AstraZeneca \\
\hline 20 & 3.8 & AstraZeneca \\
\hline \multicolumn{3}{|l|}{ Paroxetine } \\
\hline 10 & 17.1 & Aurobindo \\
\hline 20 & 55.8 & GlaxoSmithKline \\
\hline 40 & 111.5 & GlaxoSmithKline \\
\hline 10 & 147.9 & Mint Pharmaceuticals \\
\hline 20 & 295.8 & Mint Pharmaceuticals \\
\hline 30 & 443.7 & Mint Pharmaceuticals \\
\hline Azithromycin: 250 & 30.7 & Pfizer Inc \\
\hline Glyburide: 5 & 27.6 & Aurobindo \\
\hline $\begin{array}{l}\text { Megace (Megestrol } \\
\text { acetate): } 40\end{array}$ & 28.8 & Par Pharmaceutical \\
\hline \multicolumn{3}{|l|}{ Repaglinide } \\
\hline 0.5 & 7.2 & Paddock \\
\hline 1 & 9.4 & Caraco \\
\hline \multicolumn{3}{|l|}{ Sitagliptin } \\
\hline 25 & 7.3 & Merck \\
\hline 50 & 13.2 & Merck \\
\hline \multicolumn{3}{|l|}{ Sertraline } \\
\hline 50 & 4.3 & Pfizer Inc \\
\hline 100 & 8.6 & Pfizer Inc \\
\hline 25 & 2.1 & Greenstone Brand LLC \\
\hline 50 & 4.5 & Greenstone Brand LLC \\
\hline 100 & 8.7 & Greenstone Brand LLC \\
\hline Rabeprazole: 10 & 2 & Eisai China \\
\hline \multicolumn{3}{|l|}{ Bisoprolol } \\
\hline 5 & 28 & Pharmascience Inc. \\
\hline 10 & 31 & Pharmascience Inc. \\
\hline 5 & 83.6 & Sandoz Canada Inc. \\
\hline 10 & 80.1 & Sandoz Canada Inc. \\
\hline 5 & 83.5 & Sivem Pharmaceuticals \\
\hline 10 & 80.1 & Sivem Pharmaceuticals \\
\hline 5 & 61.9 & Teva Canada Ltd. \\
\hline 10 & 61.9 & Teva Canada Ltd \\
\hline 5 & 28 & Pharmascience Inc. \\
\hline 10 & 31 & Pharmascience Inc. \\
\hline 5 & 24.5 & Eon \\
\hline 10 & 23.8 & Eon \\
\hline 5 & 0 & Mylan \\
\hline 10 & 14.8 & Aurobindo \\
\hline 10 & 24.6 & Sandoz \\
\hline \multicolumn{3}{|l|}{ Zopiclone } \\
\hline 3.75 & 41.4 & Teva Canada Ltd. \\
\hline 5 & 41.4 & Teva Canada Ltd. \\
\hline 7.5 & 41.4 & Teva Canada Ltd. \\
\hline
\end{tabular}


Table 1 continued

\begin{tabular}{|c|c|c|}
\hline $\begin{array}{l}\text { Medication: } \\
\text { Dosage (mg) }\end{array}$ & $\begin{array}{l}\text { Content of Available } \\
\text { Phosphorus (mg) }\end{array}$ & Manufacturer \\
\hline \multicolumn{3}{|l|}{ Quetiapine } \\
\hline 25 & 8 & Teva Canada Ltd. \\
\hline 100 & 34 & Teva Canada Ltd. \\
\hline 150 & 25 & Teva Canada Ltd. \\
\hline \multicolumn{3}{|l|}{ Oxycodone } \\
\hline 5 & 5.21 & Pharmascience Inc. \\
\hline 10 & 4.11 & Pharmascience Inc. \\
\hline 20 & 8.22 & Pharmascience Inc. \\
\hline \multicolumn{3}{|l|}{ Acetaminophen } \\
\hline 8 mg Codeine & 60 & Teva Canada Ltd. \\
\hline 15 mg Codeine & 60 & Teva Canada Ltd. \\
\hline 30 mg Codeine & 60 & Teva Canada Ltd. \\
\hline \multicolumn{3}{|l|}{ Clonidine } \\
\hline 0.1 & 2.2 & Boehringer Ingelheim \\
\hline 0.2 & 1.4 & Blue Point Laboratories \\
\hline 0.2 & 3.5 & Unichem \\
\hline
\end{tabular}

Source: Bibliographic references ${ }^{31,35}$

followed by $24 \%$ for CV anomalies. The percentage of formulations with phosphate was very high among codeine (98\%), zopiclone (95\%), and quetiapine (73\%). In total, 31 patients (30\%) were taking at least one phosphate-containing medicine per day. Among them, the median phosphate burden from prescribed medications was reported to be $111 \mathrm{mg} /$ day, which corresponds to approximately $10 \%$ of the KDIGO-recommended daily dosage $(800-1000 \mathrm{mg})^{35,40}$.

The quantum of phosphate-containing CKD drugs was also reported by a retrospective database analysis by Sultana et al. They utilized the PubChem and other publicly available databases to confirm the presence of phosphate in the medicinal products used to treat patients with CKD. They investigated a total of 3779 medicines consumed by an Italian cohort of 1989 patients with CKD and found that 266 medicinal products containing phosphorus (7\%) were consumed by 1381 patients with CKD (70\%) over a median follow-up of 6 years. Further investigations revealed that in majority of those medications phosphate was derived from the excipient $(94.4 \%)$ rather than the active moiety $(0.8 \%)$ or the counterion $(8.3 \%)^{34}$.

One important observation made in all the above studies was the diverse amounts of phosphorus present in different formulations of the same drug, which highlights the difficulty in controlling medicinal phosphorus intake. The proportion of different groups of phosphoruscontaining medications from the reported studies is summarized in Table 2.

\section{Phosphorus content in commonly used oral drugs}

In view of the KDIGO guideline recommendations for dietary phosphorus intake in patients with CKD, the intestinal load of phosphorus through oral medications took precedence. Moreover, due to the practical difficulty involved with other routes of administration in patients with CKD, a bulk of the medicines were administered via oral route, which increases intestinal load of phosphorus.

The amount of phosphorus contributed by the prescribed medications were generally considered to be a small portion of the recommended daily intake of about $1000 \mathrm{mg} /$ day. Although a few previous studies had reported a serious concern with phosphorus content of medications, they did not report the precise nature of the phosphorus (organic or inorganic) as it may have potential ramifications in intestinal load. Moreover, the previous reports analyzed only the phosphorus content in the medicines prescribed to individual patient cohorts ${ }^{31,34}$.

In order to address this issue, Cupisti et al. conducted a systematic screening of oral medications that are commonly prescribed for patients with CKD. They utilized the Italian medicines agency database to analyze 3763 formulations of 311 distinct APIs and reported that 60 APIs (19.3\%) contained at least one phosphorus-containing excipient and a total of 472 formulations (12.5\%) contained phosphorus as an excipient. Moreover, it was observed that oral hypoglycemic drug formulations were the most phosphorus-containing drugs (23.8\%) followed by antidepressants (19.2\%), antihypertensives (17.5\%), and gastrointestinal drugs (16.4\%). The major finding of the study was that the widely used form of phosphorus in excipient was calcium hydrogen phosphate (77.57\%), which has been reported to be exhibiting a lower bioavailability $(90-70 \%)$ compared with sodium hydrogen phosphate that has a high absorption rate $(100 \%)^{36,41}$. On the basis of their finding and review of previous reports, they concluded that the phosphorus load in medications may be of concern only in a minor population with distinct medicinal requirements ${ }^{36}$. However, a comprehensive perspective on the potential effects of the additional medicinal phosphorus load in case of the phosphorus absorption and renal clearance by $\mathrm{HD}$ has to be considered.

\section{Absorption and clearance of inorganic phosphorus}

Both food additives and pharmaceutical excipients contain inorganic phosphates, which are readily absorbed from the intestine ${ }^{42-44}$, whereas in case of organic phosphates, approximately $60 \%$ is absorbed in the intestine ${ }^{42,45,46}$. Although most of the phosphorus-containing food additives such as the sodium tripolyphosphate, sodium pyrophosphate, disodium dihydrogen pyrophosphate, and sodium hexametaphosphate have a 100\% bioavailability, the calcium salts used as an excipient have a bioavailability of approximately $80 \%{ }^{41}$. Sodium salts of phosphorus are generally used as food quality-modifying, -emulsifying, -dispersing, -buffering, -chelating, -leavening, 
Table 2 Proportion of medications containing phosphate as an excipient

\begin{tabular}{|c|c|c|c|}
\hline Medications by category & $\begin{array}{l}\text { Number of formulations } \\
\text { reviewed }\end{array}$ & $\begin{array}{l}\text { Number of formulations } \\
\text { containing hosphorus }\end{array}$ & $\begin{array}{l}\text { Phosphorus-containing } \\
\text { medications (\%) }\end{array}$ \\
\hline Calcium channel blockers & 39 & 20 & 51 \\
\hline $\begin{array}{l}\text { ACE inhibitors and angiotensin-receptor } \\
\text { blockers }\end{array}$ & 89 & 9 & 10 \\
\hline Beta blockers & 39 & 9 & 23 \\
\hline Cholesterol-lowering therapy & 38 & 8 & 21 \\
\hline Pain medicines & 107 & 48 & 44.8 \\
\hline Anxiolytic agents & 42 & 0 & 0 \\
\hline Antidepressants & 173 & 10 & 5.7 \\
\hline Antipsychotics & 54 & 19 & 35.1 \\
\hline Drugs used in diabetes & 239 & 57 & 23.8 \\
\hline Psycho-analeptics & 738 & 142 & 19.2 \\
\hline Antihypertensives & 927 & 162 & 17.5 \\
\hline Drugs for acid-related disorders & 274 & 45 & 16.4 \\
\hline Thyroid therapy & 50 & 4 & 8 \\
\hline Lipid-modifying agents & 354 & 28 & 7.9 \\
\hline Analgesics & 163 & 11 & 6.7 \\
\hline Immunosuppressants & 67 & 4 & 6 \\
\hline Antihistamines for systemic use & 105 & 3 & 2.9 \\
\hline $\begin{array}{l}\text { Drugs for chronic obstructive airway } \\
\text { diseases }\end{array}$ & 394 & 9 & 2.3 \\
\hline Antithrombotic agents & 92 & 2 & 2.2 \\
\hline Cardiac therapy & 238 & 5 & 2.1 \\
\hline Anti-gout preparations & 12 & 0 & 0 \\
\hline Hormones & 69 & 12 & 17 \\
\hline Vitamins & 7 & 2 & 29 \\
\hline Gastrointestinal medications & 213 & 2 & 0.9 \\
\hline Blood coagulation andformation & 26 & 0 & 0 \\
\hline
\end{tabular}

Source: bibliographic references ${ }^{35,36}$

and -rehydrating agents and others ${ }^{47}$. On the contrary, calcium phosphate and calcium hydrogen phosphate are often used as a filler to combine pharmaceutical ingredients to form a tablet-based solid preparation ${ }^{43,44,48}$.

The amount of phosphorus contributed by medications is minor in most patients; however, in some, it is notable. In patients with CKD, as the renal clearance of phosphorus by HD is limited to approximately $1000 \mathrm{mg} / \mathrm{dia}-$ lysis session, phosphate binders are frequently used to achieve target phosphorus levels. Therefore, even a minor increase in phosphorus intake may have a disproportional effect, which could be seen from two perspectives. From an HD perspective, if a patient is consuming $10 \mathrm{mg}$ of amlodipine of Greenstone brand (phosphorus content: 27 $\mathrm{mg}), 10 \mathrm{mg}$ of lisinopril from BluePoint laboratories (phosphorus content: $32.6 \mathrm{mg}$ ), and $40 \mathrm{mg}$ of Rena-Vite (phosphorus content: $37.7 \mathrm{mg}$ ) then the phosphorus load from medication will be $110 \mathrm{mg}$, which will be $30 \%$ higher after considering the dialytic removal, which is a significant phosphorus load for patients with CKD. From the perspective of phosphorus-binding pills, the reported medicinal phosphorus load requires four additional doses of sevelamer or calcium acetate to counter the medicinal phosphorus load. ${ }^{31,33}$ However, this increased pill burden might reduce patient compliance of the prescribed medicines, resulting in lower usage of phosphorus-binder pills, which may have a compounding effect on phosphorus homeostasis ${ }^{49}$. Another important aspect of significance is 
the phosphorus content of vitamin supplements prescribed for patients with $\mathrm{CKD}^{31}$.

The estimated phosphorus load in medications in 90\% of the patients with CKD may be $<80 \mathrm{mg} /$ day, which is much lower than the phosphorus load from food additives, which could be as high as $800 \mathrm{mg}$ in certain patient populations $^{34,44}$. Nevertheless, medicinal drugs as a hidden source of phosphorus in patients with CKD cannot be neglected.

\section{Seeking alternatives}

If alternative drugs with similar safety, efficacy, and cost exist, they are preferable to be used in place of drugs with high-phosphorus content (such as lisinopril, amlodipine, and bisoprolol) in order to reduce oral phosphorus intake. The probable efficacy of low-phosphorus-containing alternatives could be seen from the perspective of daily phosphorus intake and its removal by dialysis. If a patient undergoing HD has a daily phosphorus intake of $1000 \mathrm{mg}$, and an HD clearance of about $400 \mathrm{mg} /$ day $(1000 \mathrm{mg} /$ dialytic session, thrice weekly), then there will be $600 \mathrm{mg}$ of phosphorus, of which an average of about $60 \%(360 \mathrm{mg})$ could be absorbed. If this patient takes $5 \mathrm{mg}$ of amlodipine (Pfizer) and $10 \mathrm{mg}$ of paroxetine (Aurobindo), the absorbable phosphorus will increase by approximately $8.5 \%(30.5 \mathrm{mg})$, which is equivalent to $16.1 \mathrm{~g}$ of pork $(\text { thin })^{31}$. If both drugs are replaced by alternatives, the intestinal phosphorus load could be decreased by $8.5 \%$, which is a substantial reduction of phosphorus load in patients with CKD. Among the potential alternatives, perindopril, nifedipine, and felodipine have not been reported to contain phosphorus as an excipient ${ }^{35}$. Therefore, perindopril, which is an angiotensinconverting enzyme inhibitor, could be used instead of lisinopril. Similarly, nifedipine and felodipine, which are calcium channel blockers, could be used as potential alternatives to amlodipine ${ }^{50,51}$. Currently, there is a lack of transparency in declaring the excipient phosphorus content by pharmaceutical manufacturers, which slows down the search for alternatives. Therefore, to begin with, all the medications marketed should specify the information regarding the phosphorus content and warnings on its implications on health to both physicians and the dialysis community.

\section{Lowering dietary phosphorus intake}

Although dietary phosphorus consists of organic phosphorus from plant source (e.g., phytates) and animal source (e.g., casein), and inorganic phosphorus (e.g., food additives), only inorganic phosphorus is absorbed from the intestine. The dietary organic phosphorus is converted to inorganic form by intestinal enzymes, which leads to differential absorption of phosphorus from different sources. In case of inorganic phosphorus, $80-100 \%$ is rapidly absorbed, whereas only $40-60 \%$ of organic phosphorus is absorbed after conversion into inorganic phosphorus $^{52-54}$. Similarly, plant-based organic phosphorus has a low bioavailability (20-40\%) as the majority of the phosphorus exists as storage molecule called phytates. Phytates cannot be broken down by humans due to the lack of hydrolyzing enzymes ${ }^{55}$, whereas larger portion of animal-derived phosphorus is present bound to organic molecules such as proteins, phospholipids, and nucleic acids and hence it is easily hydrolyzed and absorbed and has a higher bioavailability $(40-60 \%)^{56-58}$. Therefore, theoretically, vegetarian diet has a lower phosphate-toprotein ratio leading to decreased phosphorus absorption in comparison with animal-based diet. In a preclinical study, animals fed with grain-based diet had lower serum level of FGF23 and urinary phosphorus excretion when compared with standard synthetic casein-based diet ${ }^{59}$. In a crossover trial of two diets (vegetarian and meat/dairy) in patients with CKD stage late 3 or stage 4, lower serum phosphorus, FGF23 levels, and decreased urinary phosphorus excreted during 24-h excretion was observed in the vegetarian diet compared with the meat-based $\operatorname{diet}^{58}$.

In clinical studies, FGF23 was considered as a surrogate marker for serum phosphorus due to its close association in phosphorus homeostasis. The beneficial role of lowphosphorus diet has also been reported from numerous randomized controlled trials (RCTs $)^{50,51}$. Sequestering excess dietary phosphorus using phosphorus binders has also been evaluated as a clinical management strategy. The combined efficacy of low-phosphorus diet and phosphorus binders was evaluated by Isakova et al. ${ }^{51}$ and it was reported that diet combined with phosphate binders was more effective in reducing FGF23 and serum phosphorus compared with single approach. Lowering dietary phosphorus and phosphorus binders were the cornerstone of clinical management. However, poor adherence of patients to phosphorus-restricted diet and hidden sources of phosphorus has reduced the efficacy of this strategy ${ }^{58}$.

\section{Diet with low phosphorus-protein ratio}

The strategy of maintaining low dietary phosphorus might seem straight forward; however, the major source of dietary phosphorus is proteins, which if restricted, might lead to malnutrition. In addition, it is also a risk factor for death in patients with $C K D^{25,60}$. The estimated phosphorus load from $1 \mathrm{~g}$ of protein is around $13-15 \mathrm{mg}$, out of which $30-70 \%$ is absorbed through intestine. Therefore, a $90-\mathrm{g}$ daily intake of protein provides $600-700 \mathrm{mg}$ of phosphorus, which is $70 \%$ of the daily recommended intake ${ }^{40,61}$. Therefore, restriction of protein intake being safe both nutritionally and metabolically, it decreases the level of serum phosphorus and slows down the progression of $\mathrm{CKD}^{62-64}$. Evidence supporting 
the benefits of low-protein diet was also provided by a meta-analysis by Fouque et al. ${ }^{65}$, which reported that a low-protein diet containing $0.6-0.8 \mathrm{~g}$ protein $/ \mathrm{kg} /$ day reduces the risk of premature death or kidney replacement by $32 \%$.

In view of the risk of malnutrition and subsequent CKD progression, average protein intake in patients with CKD is measured in terms of normalized protein catabolic rate (nPCR), which is a measure of protein nutritional status ${ }^{66}$. A previous study conducted by Shinaberger et al. reported the best survival rate among patients with normalized protein nitrogen appearance (nPNA or nPCR) between 1.0 and $1.4 \mathrm{~g} / \mathrm{kg} /$ day whereas greater mortality was observed in nPNA $<0.8$ or $>1.4 \mathrm{~g} / \mathrm{kg} / \mathrm{day}^{26,67}$. Streja et al. ${ }^{67}$ emphasized the interaction between dietary protein intake, PTH levels, and serum phosphorus levels; however, it did not advocate on reducing the nPCR and PTH levels as management strategies for hyperphosphatemia. Furthermore, limiting protein intake is associated with increased risk of death in patients with CKD and MBD as it leads to malnutrition ${ }^{68,69}$.

Therefore, in recent years, studies have recommended the use of phosphorus/protein ratio as an indicator of measuring phosphorus content in food. The concept of phosphorus/protein ratio was proposed by the Kidney Disease Outcomes Quality Initiative (K/DOQI) guidelines for patients with kidney disease to support nutritional counseling and control blood phosphorus levels through $\operatorname{diet}^{3,40}$. It is a metric representing ratio of dietary phosphorus (in $\mathrm{mg}$ ) to protein (in $\mathrm{g}$ ) for a given food item, which may be more suitable for patients with CKD compared with total protein intake (nPCR). The guideline lists the phosphorus/protein ratios in common food items, which could be used for prescribing healthy diet in patients with CKD. As per the guidelines, dairy products, nuts, beans, and seeds have a high phosphorus-protein ratio and should be avoided. Similarly, meat and tofu have a low phosphorus-protein ratio and are preferable ${ }^{70}$. Guida et al. ${ }^{71}$ used low-phosphorus whey protein concentrate to replace dietary proteins for a short period and observed significant decrease in blood phosphorus and PTH levels, whereas nutrient-related indicators such as albumin did not change significantly. Similarly, Watanabe et al. ${ }^{24}$ found that processed foods contain more protein and phosphate and the higher phosphorus-protein ratio compared with fresh foods. There are various other studies summarizing the protein and phosphorus content and phosphorus-protein ratio of different food stuffs ${ }^{56,72,73}$. In an RCT conducted on patients with ESRD undergoing HD, there was a decrease in serum phosphorus concentration after nutritional counseling on restricting the diet with phosphorus additives and replacing these foods with those with similar nutritional value without the phosphorus additives ${ }^{74}$. Therefore, patients with CKD should be encouraged to consume fresh unprocessed food instead of processed food. In the absence of additive interference, lower the phosphorus-protein ratio, lower the likelihood of hyperphosphatemia. Therefore, patients with CKD who have hyperphosphatemia should choose foods with low phosphorus absorption and low phosphorus-protein ratio ${ }^{75}$.

For educating patients regarding low-phosphorus diet, phosphorus-protein ratio $>12 \mathrm{mg} / \mathrm{g}$ could be considered as "high-phosphorus food" and $<12 \mathrm{mg} / \mathrm{g}$ is "low-phosphorus food," for example, egg white has a phosphorus-protein ratio of only $1.4 \mathrm{mg} / \mathrm{g}$ which is classified as a low-phosphorus food, whereas egg yolk has $23 \mathrm{mg} / \mathrm{g}$, which is a high-phosphorus food ${ }^{56,72}$. Some methods followed during cooking, such as soaking foods in water and boiling them helps to reduce the dietary phosphorus content per gram of protein in foods ${ }^{72}$. Therefore, it is recommended that patients with CKD choose foods with a low phosphorus-protein ratio, but with adequate amount of protein to prevent malnutrition, limit the intake of foods high in phosphorous additives, and use of better phosphate binders for the better management of hyperphosphatemia in CKD.

\section{Summary}

Patients with CKD usually consume a variety of oral medications, and these medications may significantly increase phosphorus intake. The lack of transparency by the pharmaceutical manufacturers in providing information on the phosphorus content of the drugs increases the uncertainty of hyperphosphatemia management in patients with CKD. The only way to prevent the risk of phosphorus-containing medications in patients with CKD is by educating doctors and patients on the presence and concentration of phosphorus in the pharmaceutical products. Therefore, pharmaceutical manufacturers should report the phosphorus content/quantity of their products more transparently and in a greater detail. Nephrologists should also take extra caution regarding the phosphorus content of the drugs for patients with CKD to provide evidence-based guidance and management. In addition, the importance of a low phosphorus-protein-ratio diet should be emphasized in dietary education for patients with CKD.

\section{Acknowledgements}

We gratefully acknowledge all the clinicians who contributed to the study. Medical writing support, under the direction of authors, was provided by Dr. S. Vedashree, Ph.D.; Dr. G. Kaushik Subramanian, Ph.D.; and Dr. Amit Bhat, Ph.D. (Indegene Pvt Ltd, Bangalore). This study was funded by Bayer. This research was financially sponsored by the National Natural Science Foundation of China (No. 51433007-1) and the State Key Research Development Programme of China (2016YFC1103004).

\section{Authors' contributions}

J.L. and L.W. wrote this manuscript and tabulated the two lists of medications. All authors have given their approval to the final version of this manuscript. 


\section{Conflict of interest}

The authors declare that they have no conflict of interest.

\section{Publisher's note}

Springer Nature remains neutral with regard to jurisdictional claims in published maps and institutional affiliations.

\section{Received: 31 October 2018 Revised: 5 March 2019 Accepted: 12 March} 2019 Published online: 03 April 2019

\section{References}

1. Moe, S. et al. Definition, evaluation, and classification of renal osteodystrophy: a position statement from Kidney Disease: Improving Global Outcomes (KDIGO). Kidney Int. 69, 1945-1953 (2006).

2. Seifert, M. E. \& Hruska, K. A. The kidney-vascular-bone axis in the chronic kidney disease-mineral bone disorder. Transplantation 100, 497-505 (2016).

3. Kidney Disease: Improving Global Outcomes (KDIGO) CKD-MBD Work Group. $\mathrm{KDIGO}$ clinical practice guideline for the diagnosis, evaluation, prevention, and treatment of Chronic Kidney Disease-Mineral and Bone Disorder (CKD-MBD). Kidney Int. 113, (Suppl.), S1-S130 (2009).

4. Isakova, T. et al. Fibroblast growth factor 23 is elevated before parathyroid hormone and phosphate in chronic kidney disease. Kidney Int. 79, 1370-1378 (2011).

5. Shimada, T. et al. Targeted ablation of Fgf23 demonstrates an essential physiological role of FGF23 in phosphate and vitamin D metabolism. J. Clin. Invest. 113, 561-568 (2004)

6. Liu, S. \& Quarles, L. D. How fibroblast growth factor 23 works. J. Am. Soc. Nephrol. 18, 1637-1647 (2007).

7. Hong, Y. A. et al. Assessment of tubular reabsorption of phosphate as a surrogate marker for phosphate regulation in chronic kidney disease. Clin. Exp. Nephrol. 19, 208-215 (2015).

8. Antoniucci, D. M., Yamashita, T. \& Portale, A. A. Dietary phosphorus regulates serum fibroblast growth factor-23 concentrations in healthy men. J. Clin. Endocrinol. Metab. 91, 3144-3149 (2006).

9. Ramos, A. M., et al. Hyperphosphatemia and hyperparathyroidism in incident chronic kidney disease patients. Kidney Int. 74, (Suppl.), S88-S93 (2008).

10. Gonzalez-Parra, E., Tuñón, J., Egido, J. \& Ortiz, A. Phosphate: a stealthier killer than previously thought? Cardiovasc. Pathol. 21, 372-381 (2012).

11. London, G. M. et al. Arterial media calcification in end-stage renal disease: impact on all-cause and cardiovascular mortality. Nephrol. Dial. Transplant. 18, 1731-1740 (2003).

12. Marchais, S. J., Metivier, F., Guerin, A. P. \& London, G. M. Association of hyperphosphataemia with haemodynamic disturbances in end-stage renal disease. Nephrol. Dial. Transplant. 14, 2178-2183 (1999).

13. Block, G. A., Raggi, P., Bellasi, A., Kooienga, L. \& Spiegel, D. M. Mortality effect of coronary calcification and phosphate binder choice in incident hemodialysis patients. Kidney Int. 71, 438-441 (2007).

14. Hruska, K. A., Mathew, S., Lund, R., Qiu, P. \& Pratt, R. Hyperphosphatemia of chronic kidney disease. Kidney Int. 74, 148-157 (2008).

15. Block, G., Hulbert-Shearon, T., Levin, N. \& Port, F. Association of serum phosphorus and calcium $x$ phosphate product with mortality risk in chronic hemodialysis patients: a national study. Am. J. Kidney Dis. 31, 607-617 (1998).

16. Zhang, C., Wen, J., Li, Z. \& Fan, J. Efficacy and safety of lanthanum carbonate on chronic kidney disease-mineral and bone disorder in dialysis patients: a systematic review. BMC Nephrol. 14, 226 (2013).

17. Tentori, F. et al. Mortality risk for dialysis patients with different levels of serum calcium, phosphorus, and PTH: The Dialysis Outcomes and Practice Patterns Study (DOPPS). Am. J. Kidney Dis. 52, 519-530 (2008).

18. Wald, R. et al. Disordered mineral metabolism in hemodialysis patients: an analysis of cumulative effects in the hemodialysis (HEMO) Study. Am. J. Kidney Dis. 52, 531-540 (2008).

19. Eddington, $\mathrm{H}$. et al. Serum phosphate and mortality in patients with chronic kidney disease. Clin. J. Am. Soc. Nephrol. 5, 2251-2257 (2010).

20. Ganesh, S. K., Stack, A. G., Levin, N. W., Hulbert-Shearon, T. \& Port, F. K. Association of elevated serum $\mathrm{PO} 4$, CaxPO4 product, and parathyroid hormone with cardiac mortality risk in chronic hemodialysis patients. J. Am. Soc. Nephrol. 12, 2131-2138 (2001).
21. Naves-Díaz, M. et al. Calcium, phosphorus, PTH and death rates in a large sample of dialysis patients from Latin America. The CORES Study. Nephrol. Dial. Transplant. 26, 1938-1947 (2011).

22. Floege, J. et al. Serum iPTH, calcium and phosphate, and the risk of mortality in a European haemodialysis population. Nephrol. Dial. Transplant. 26, 1948-1955 (2011).

23. Palmer, S. C. et al. Serum levels of phosphorus, parathyroid hormone, and calcium and risks of death and cardiovascular disease in individuals with chronic kidney disease: a systematic review and meta-analysis. JAMA 305, 1119-1127 (2011)

24. Watanabe, M. T., Araujo, R. M., Vogt, B. P., Barretti, P. \& Caramori, J. C. T. Most consumed processed foods by patients on hemodialysis: alert for phosphatecontaining additives and the phosphate-to-protein ratio. Clin. Nutr. ESPEN 14, 37-41 (2016).

25. Shinaberger, C. S. et al. Is controlling phosphorus by decreasing dietary protein intake beneficial or harmful in individuals with chronic kidney disease? Am. J. Clin. Nutr. 88, 1511-1518 (2008).

26. Shinaberger, C. S. et al. Longitudinal associations between dietary protein intake and survival in hemodialysis patients. Am. J. Kidney Dis. 48, 37-49 (2006).

27. Takeda, E., Yamamoto, H., Yamanaka-Okumura, H. \& Taketani, Y. Increasing dietary phosphorus intake from food additives: potential for negative impact on bone health123. Adv. Nutr. 5, 92-97 (2014)

28. Navaneethan, S. D., et al. Phosphate binders for preventing and treating bone disease in chronic kidney disease patients. Cochrane Database Syst. Rev. CD006023 (2011). https://doi.org/10.1002/14651858.CD006023.pub2.

29. Andrassy, K. M. Comments on 'KDIGO 2012 clinical practice guideline for the evaluation and management of chronic kidney disease'. Kidney Int. 84, 622-623 (2013).

30. Elias, R. M., Alvares, V. R. C. \& Moysés, R. M. A. Phosphate removal during conventional hemodialysis: a decades-old misconception. Kidney Blood Press. Res. 43, 110-114 (2018).

31. Sherman, R. A., Ravella, S. \& Kapoian, T. The phosphate content of prescription medication: a new consideration. Drug Inf. J. 49, 886-889 (2015).

32. Shimoishi, K. et al. A comparison of the phosphorus content in prescription medications for hemodialysis patients in Japan. Yakugaku Zasshi 137, 903-908 (2017).

33. Sherman, R. A., Ravella, S. \& Kapoian, T. A dearth of data: the problem of phosphorus in prescription medications. Kidney Int. 87, 1097-1099 (2015).

34. Sultana, J. et al. Medication is an additional source of phosphate intake in chronic kidney disease patients. Nutr. Metab. Cardiovasc. Dis. 25, 959-967 (2015).

35. Nelson, S. M. L. et al. Phosphate-containing prescription medications contribute to the daily phosphate intake in a third of hemodialysis patients. J. Ren. Nutr. 27, 91-96 (2017).

36. Cupisti, A. et al. The extra-phosphate intestinal load from medications: is it a real concern? J. Nephrol. 29, 857-862 (2016).

37. Ballentine, C. Taste of raspberries, taste of death: the 1937 elixir sulfanilamide incident. FDA Consumer Magazine (1981). http://www.fda.gov/oc/history/elixir. html. Accessed 24 Jul 2018).

38. Chiu, Y.-W. et al. Pill burden, adherence, hyperphosphatemia, and quality of life in maintenance dialysis patients. Chin. J. Am. Soc. Nephrol. 4, 1089-1096 (2009).

39. Manley, H. J., Cannella, C. A., Bailie, G. R. \& St Peter, W. L. Medication-related problems in ambulatory hemodialysis patients: a pooled analysis. Am. J. Kidney Dis. 46, 669-680 (2005).

40. Isakova, T. et al. KDOQI US commentary on the $2017 \mathrm{KDIGO}$ clinical practice guideline update for the diagnosis, evaluation, prevention, and treatment of chronic kidney disease-mineral and bone disorder (CKD-MBD). Am. J. Kidney Dis. 70, 737-751 (2017).

41. Wendt, P. \& Rodehutscord, M. Investigations on the availability of inorganic phosphate from different sources with growing White Pekin ducks. Poult. Sci. 83, 1572-1579 (2004).

42. Sherman, R. A. \& Mehta, O. Dietary phosphorus restriction in dialysis patients: potential impact of processed meat, poultry, and fish products as protein sources. Am. J. Kidney Dis. 54, 18-23 (2009).

43. Carrigan, A., et al. Contribution of food additives to sodium and phosphorus content of diets rich in processed foods. J. Ren. Nutr. 24 (2014). https://doi.org/ 10.1053/j.jn.2013.09.003.

44. León, J. B., Sullivan, C. M. \& Sehgal, A. R. The prevalence of phosphorus containing food additives in top selling foods in grocery stores. J. Ren. Nutr. 23, 265.e2-270.e2 (2013).

45. Ramirez, J. A. et al. The absorption of dietary phosphorus and calcium in hemodialysis patients. Kidney Int. 30, 753-759 (1986). 
46. Sherman, R. A. \& Mehta, O. Phosphorus and potassium content of enhanced meat and poultry products: implications for patients who receive dialysis. Clin. J. Am. Soc. Nephrol. 4, 1370-1373 (2009).

47. Lee, B. J., Hendricks, D. G. \& Cornforth, D. P. Effect of sodium phytate, sodium pyrophosphate and sodium tripolyphosphate on physico-chemical characteristics of restructured beef. Meat Sci. 50, 273-283 (1998).

48. Sullivan, C. M., Leon, J. B. \& Sehgal, A. R. Phosphorus containing food additives and the accuracy of nutrient databases: implications for renal patients. J. Ren. Nutr. 17, 350-354 (2007)

49. Wang, S., Alfieri, T., Ramakrishnan, K., Braunhofer, P. \& Newsome, B. A. Serum phosphorus levels and pill burden are inversely associated with adherence in patients on hemodialysis. Nephrol. Dial. Transplant. 29, 2092-2099 (2014).

50. Iorio, B. D. et al. Acute effects of very-low-protein diet on FGF23 levels: a randomized study. Chin. J. Am. Soc. Nephrol. 7, 581-587 (2012).

51. Isakova, T. et al. Effects of dietary phosphate restriction and phosphate binders on FGF23 levels in CKD. Clin. J. Am. Soc. Nephrol. 8, 1009-1018 (2013).

52. Bell, R. R., Draper, H. H., Tzeng, D. Y., Shin, H. K. \& Schmidt, G. R. Physiological responses of human adults to foods containing phosphate additives. J. Nutr. 107, 42-50 (1977).

53. Karp, H. J., Vaihia, K. P., Kärkkäinen, M. U. M., Niemistö, M. J. \& Lamberg-Allardt, C. J. E. Acute effects of different phosphorus sources on calcium and bone metabolism in young women: a whole-foods approach. Calcif. Tissue Int. $\mathbf{8 0}$ 251-258 (2007).

54. Kalantar-Zadeh, K. Patient education for phosphorus management in chronic kidney disease. Patient Prefer Adherence 7, 379-390 (2013).

55. St-Jules, D. E., Jagannathan, R., Gutekunst, L., Kalantar-Zadeh, K. \& Sevick, M. A Examining the proportion of dietary phosphorus from plants, animals and food additives excreted in urine. J. Ren. Nutr. 27, 78-83 (2017).

56. Kalantar-Zadeh, K. et al. Understanding sources of dietary phosphorus in the treatment of patients with chronic kidney disease. Chin. J. Am. Soc. Nephrol. 5 519-530 (2010).

57. Noori, N. et al. Organic and inorganic dietary phosphorus and its management in chronic kidney disease. Iran. J. Kidney Dis. 4, 89-100 (2010).

58. Moe, S. M. et al. Vegetarian compared with meat dietary protein source and phosphorus homeostasis in chronic kidney disease. Clin. J. Am. Soc. Nephrol. 6 257-264 (2011).

59. Moe, S. M. et al. A rat model of chronic kidney disease-mineral bone disorder. Kidney Int. 75, 176-184 (2009).

60. Rufino, M. et al. Is it possible to control hyperphosphataemia with diet, without inducing protein malnutrition? Nephrol. Dial. Transplant. 13, 65-67 (1998).

61. González-Parra, E., Gracia-lguacel, C., Egido, J. \& Ortiz, A. Phosphorus and nutrition in chronic kidney disease. Int. J. Nephrol. (2012). https://doi.org/ $10.1155 / 2012 / 597605$.
62. Bernhard, J., Beaufrère, B., Laville, M. \& Fouque, D. Adaptive response to a lowprotein diet in predialysis chronic renal failure patients. J. Am. Soc. Nephrol. 12 1249-1254 (2001).

63. Levey, A. S. et al. Effects of dietary protein restriction on the progression of advanced renal disease in the Modification of Diet in Renal Disease Study. Am. J. Kidney Dis. 27, 652-663 (1996).

64. Levey, A. S. et al. Dietary protein restriction and the progression of chronic renal disease: what have all of the results of the MDRD study shown? Modification of Diet in Renal Disease Study group. J. Am. Soc. Nephrol. 10, 2426-2439 (1999).

65. Fouque, D., Wang, P., Laville, M. \& Boissel, J.-P. Low protein diets delay endstage renal disease in non-diabetic adults with chronic renal failure. Nephrol. Dial. Transplant. 15, 1986-1992 (2000).

66. Chandna, S. M., Kulinskaya, E. \& Farrington, K. A dramatic reduction of normalized protein catabolic rate occurs late in the course of progressive renal insufficiency. Nephrol. Dial. Transplant. 20, 2130-2138 (2005).

67. Streja, E. et al. Hyperphosphatemia is a combined function of high serum PTH and high dietary protein intake in dialysis patients. Kidney Int. $\mathbf{3}$ (Suppl.), 462-468 (2013).

68. Kalantar-Zadeh, K. \& Ikizler, T. A. Let them eat during dialysis: an overlooked opportunity to improve outcomes in maintenance hemodialysis patients. J. Ren. Nutr. 23, 157-163 (2013).

69. Kovesdy, C. P., Kopple, J. D. \& Kalantar-Zadeh, K. Management of proteinenergy wasting in non-dialysis-dependent chronic kidney disease: reconciling low protein intake with nutritional therapy. Am. J. Clin. Nutr. 97, 1163-1177 (2013).

70. Eknoyan, G., Levin, A. \& Levin, N. W. Bone metabolism and disease in chronic kidney disease. Am. J. Kidney Dis. 42, 1-201 (2003).

71. Guida, B. et al. Dietary phosphate restriction in dialysis patients: a new approach for the treatment of hyperphosphataemia. Nutr. Metab. Cardiovasc Dis. 21, 879-884 (2011).

72. Sinha, A. \& Prasad, N. Dietary management of hyperphosphatemia in chronic kidney disease. Clin. Queries Nephrol. 3, 38-45 (2014)

73. Barril-Cuadrado, G., Puchulu, M. B. \& Sánchez-Tomero, J. A. Table showing dietary phosphorus/protein ratio for the Spanish population. Usefulness in chronic kidney disease. Nefrologia 33, 362-371 (2013).

74. de Fornasari, M. L. L. \& Dos Santos Sens, Y. A. replacing phosphorus-containing food additives with foods without additives reduces phosphatemia in end stage renal disease patients: a randomized clinical trial. J. Ren. Nutr. 27, 97-105 (2017).

75. Hwang, E., Choi, B. S., Oh, K.-H., Kwon, Y. J. \& Kim, G.-H. Management of chronic kidney disease-mineral and bone disorder: Korean working group recommendations. Kidney Res. Clin. Pract. 34, 4-12 (2015). 